\title{
ARTÍCULO
}

\section{Incompatibilismo humanista: Una contrapropuesta del neuroabolicionismo penal}

\section{Humanistic incompatibilism: A counterproposal of penal neuroabolitionism}

\author{
Diego Borbón \\ Universidad Externado de Colombia \\ https://orcid.org/0000-0002-2115-2105
}

Fecha de recepción 30/03/2021 | De aceptación: 08/10/2021 | De publicación: 23/12/2021

\section{RESUMEN.}

El incompatibilismo humanista sostiene que el libre albedrío es un concepto incompatible con las verdades deterministas e indeterministas de la ciencia, pero plantea la dignidad humana como límite a cualquier desarrollo de la ciencia y la justicia. El presente artículo realiza un recorrido histórico y conceptual alrededor del determinismo, indeterminismo, compatibilismo e incompatibilismo. Posteriormente, introduce al problema que la neurociencia provoca para la teoría del delito y la culpabilidad penal. Más adelante, presenta algunas críticas al compatibilismo humanista y postula al incompatibilismo humanista como una contrapropuesta abolicionista del derecho penal. El artículo finaliza con la formulación de cinco postulados básicos de una nueva corriente abolicionista: el neuroabolicionismo penal, y se exponen las conclusiones.

\section{PALABRAS CLAVE.}

Libre albedrío; Compatibilismo; Incompatibilismo; Abolicionismo penal; Neuroabolicionismo penal; Culpabilidad.

\section{ABSTRACT.}

Humanistic incompatibilism holds that free will is a concept incompatible with the deterministic and indeterministic truths of science but raises the human dignity as a limit to any development of science and justice. This article makes a historical and conceptual journey around determinism, indeterminism, compatibilism and incompatibilism. Later, it introduces the problem that neuroscience creates for the theory of crime. Then, it presents some criticisms to humanistic compatibilism and posits humanistic incompatibilism as an abolitionist counterproposal of criminal law. The article ends with the formulation of five basic postulates of penal neuroabolitionism and presents the conclusions.

\section{KEY WORDS.}

Free will; Compatibilism; Incompatibilism; Penal abolitionism; Penal neuroabolitionism; Culpability. 
Sumario: 1. Introducción; 2. Determinismo; 3. Indeterminismo; 4. Compatibilismo e Incompatibilismo; 5. La neurociencia: un nuevo problema para el derecho penal; 6. El compatibilismo humanista; 7. El incompatibilismo humanista: una contrapropuesta del neuroabolicionismo penal, 7.1 Sin libre albedrío no puede existir el derecho penal de la culpabilidad, 7.2 Existen alternativas humanas al derecho penal, 7.3 La prisión causa efectos neuropsicológicos negativos y debe abolirse, 7.4 La neurociencia, la criminología y la sociología pueden prevenir, 7.5 El incompatibilismo humanista como límite; 8. Conclusiones.

\section{Introducción}

El libre albedrío es un concepto que involucra gran parte de las cosas que nos importan como seres humanos. Siguiendo a Samuel B. Harris, el libre albedrío involucra "la moralidad, la ley, la política, la religión, las políticas públicas, las relaciones íntimas, los sentimientos de culpa y la realización personal: la mayor parte de lo que es distintivamente humano en nuestras vidas parece depender de que nos veamos unos a otros como personas autónomas, capaces de elegir libremente". ${ }^{1}$ La creencia de que el libre albedrío existe nos hace sentir autores de nuestras propias acciones, en control de lo que hacemos, y de que pudimos haber actuado de manera distinta a como lo hicimos en el pasado o como lo habremos hecho en el futuro.

Sin embargo, frente a las realidades del determinismo o del indeterminismo, se ha puesto en serias dudas la posibilidad de seguir sosteniendo la idea del libre albedrío. De la misma manera, los avances en las neurociencias han aportado significativas investigaciones con neurotecnologías que parecen soportar la tesis de que el libre albedrío, por lo menos en un sentido tradicional, no puede existir.

Para analizar esto, el presente artículo realiza un recorrido histórico y conceptual alrededor del determinismo causalista, indeterminismo, compatibilismo e incompatibilismo. Posteriormente, se presenta al incompatibilismo humanista como una contrapropuesta a la realizada en el año 2013 por el profesor Eduardo Demetrio Crespo, denominado compatibilismo humanista, como conciliación entre neurociencia y derecho penal. Por el contrario, se sostiene que el incompatibilismo humanista produce la crisis absoluta del principio de culpabilidad, y con ello, conduce en efecto dominó a la supresión del derecho penal.

En ese sentido, se sostendrá que el incompatibilismo humanista es una tesis que emplea los avances científicos para comprender la imposibilidad de seguir manteniendo nociones arcaicas de responsabilidad

\footnotetext{
${ }^{1}$ HARRIS, S.; Free will, Nueva York, Simon \& Schuster, 2012, p.1.
} 
penal y moral a partir de la refutación del dogma del libre albedrío. Los dominantes paradigmas científicos sobre el determinismo y el indeterminismo excluirían, ambos, la posibilidad metafísica de la noción tradicional de libre albedrío como opciones alternativas y control último. Es por esto que, lejos de ser la base para tesis peligrosistas o expansivas del derecho penal, el incompatibilismo humanista busca comprender científicamente los orígenes neurobiológicos, ambientales, sociales y culturales del comportamiento humano para crear verdaderas políticas criminales con política social y salud mental.

A partir de ello, el neuroabolicionismo penal debe surgir como una propuesta de política criminal para el futuro, construida con base en evidencia y pilares científicos, para complementar al abolicionismo sociológico que bien ha señalado la ilegitimidad del derecho penal. En ese sentido, los postulados básicos que serán desarrollados a profundidad en trabajos futuros sostienen que: sin libre albedrío no puede haber derecho penal de culpabilidad; que la prisión genera efectos neuropsicológicos adversos, inhumanos, y debe abolirse; que existen mejores alternativas civiles, restaurativas, terapéuticas, comunitarias e indígenas al derecho penal; que la neurociencia, la criminología y la sociología pueden estudiar científicamente el comportamiento humano y prevenir; y que la dignidad humana es un límite de la justicia y la ciencia.

\section{Determinismo}

En términos globales, el determinismo implica que el mundo está bajo el dominio del determinismo si, dada una determinada forma en que las cosas son en un tiempo, la forma en que las cosas van a ser a partir de entonces es fija, es decir, están determinadas a ser como una cuestión de ley natural. ${ }^{2}$ Si bien enmarcaremos este debate desde la física con el determinismo de la mecánica clásica, cuyos cimientos se construyen con Newton y Laplace, las discusiones sobre el determinismo se remontan milenios atrás desde la filosofía presocrática. Desde los atomistas Leucipo de Mileto y Demócrito, pasando por los estoicos, hasta las perspectivas religiosas de Spinoza, se van desarrollando interesantes teorías sobre el determinismo y el sentido de la vida.

No sería hasta los planteamientos de la mecánica clásica con Isaac Newton y Pierre-Simon Laplace, que se esbozaron claras leyes científicas que plantearon la visión de un universo causalista, determinista y mecanicista. Bajo la perspectiva de la mecánica clásica, el universo es determinista en razón a que sigue

${ }^{2}$ HOEFER, C.; “Causal Determinism”, The Stanford Encyclopedia of Philosophy. Edward N. Zalta (ed.), 2016. 
una serie de causas desde la creación del espacio y tiempo que podría hacer predecibles todos los eventos futuros. Tal como lo sostiene Laplace en su Ensayo filosófico sobre probabilidades, donde ejemplifica que el pasado y el futuro no sería incierto, estaría presente, para una inteligencia que pudiese conocer todas las fuerzas que animan la naturaleza. ${ }^{3}$

Por su parte, Isaac Newton, físico, matemático e inventor inglés, publicó en 1687 su obra maestra Philosophice naturalis principia mathematica, considerada dentro de las más importantes para la física. En ella Newton plasmó, entre otras cosas, las tres Leyes del movimiento y la ley de la gravitación universal. Feldman resalta que la segunda Ley del movimiento de Newton explica que el movimiento es determinista al comprender cómo los objetos se mueven de la forma en que lo hacen debido a las fuerzas que actúan sobre ellos. ${ }^{4}$ Es importante resaltar que, si bien en la experiencia diaria estas leyes perduran, la física emplea la mecánica cuántica en objetos nanométricos; la relatividad especial para objetos muy rápidos; y la relatividad general para objetos significativamente grandes como estrellas o galaxias.

Lo cierto es que bajo la perspectiva del determinismo causalista, sólo existe una forma como se desenvuelven los eventos determinados por la cadena de causas precedentes. Es por eso que, si el ser humano está compuesto de materia sujeta a las leyes de la física, el determinismo es verdad y todo lo que un individuo hará hacia futuro no podrá ser de manera distinta a como efectivamente acontecerá. El encéfalo, como órgano compuesto principalmente de células neuronales y gliales, es materia sujeta a las leyes deterministas de la física.

Samuel B Harris, en su libro sobre el libre albedrío afirma que "sabemos que el determinismo, en cualquier sentido relevante para el comportamiento humano, es verdad". 5 Lo anterior en razón a la certeza de que los eventos neuronales determinan nuestras acciones y estos eventos, asimismo, están determinados por causas precedentes de las que somos subjetivamente inconscientes.

Esta concepción, sostiene que son el conjunto de las leyes de la física las que gobiernan el universo material, por su parte, rechaza la posibilidad de que algo sea causa sui, es decir, su propia causa libre. El ser humano, por consiguiente, para poder escapar a las verdades del determinismo causalista, tendría que

\footnotetext{
${ }^{3}$ LAPLACE, P.; A Philosophical Essay on Probabilities, Londres, Chapman \& Hall, Limited, 1902.

${ }^{4}$ FELDMAN, D.; Chaos and Fractals: An Elementary Introduction, Oxford, Oxford University Press, 2012.

${ }^{5}$ HARRIS, S.; Free will, Nueva York, Simon \& Schuster, 2012, p.8.
} 
tener la capacidad de quebrantar la cadena de causas precedentes y poder causar su propia causa. Sin embargo, para que algo así fuese posible, sería necesaria la intervención de alguna substancia inmaterial que no pueda estar sujeta a las leyes deterministas de la física, como la idea mística del alma, tesis que se la reservamos a la teología. Si no hay un fantasma detrás de la máquina, un pequeño homúnculo dentro de nuestro encéfalo que es el verdadero yo, o que nuestra alma se halle en la glándula pineal, como afirmaba Descartes, por supuesto debemos rechazar la posibilidad de que el ser humano posea una característica mística que le permita causar su propia causa.

Ahora bien, sostener en el siglo XXI la tesis de un absoluto determinismo causalista como la única verdad de la física en el universo sería un absurdo. Es por ello que debemos adentrarnos en el indeterminismo y esbozar sumariamente los desarrollos de la mecánica cuántica. Para ello es relevante hacer una breve alusión al concepto del indeterminismo, a los planteamientos generales de la mecánica cuántica, así como preguntarse si es posible que en el encéfalo humano intervenga la incertidumbre y la probabilidad de la mecánica cuántica.

\section{Indeterminismo}

La mecánica cuántica es la teoría fundamental que describe las propiedades de átomos, partículas subatómicas, moléculas y ensamblajes moleculares ${ }^{6}$, al operar en las escalas micro, pero esencialmente en las nanométricas ${ }^{7}$ y subnanométricas. Si bien en un nivel fundamental se puede decir que todos los sistemas biológicos serían mecánico-cuánticos, estando compuestos de átomos y, por tanto, sujetos a la teoría cuántica, durante muchas décadas la postura dominante en las ciencias fue la de rechazar la interferencia de los efectos cuánticos de las pequeñísimas escalas nanométricas en el encéfalo humano. ${ }^{8}$ Por otra parte, en términos generales, un conjunto basto de distintos componentes cuánticos forma un cuerpo de escalas macroscópicas que puede describirse con mucha precisión usando la física clásica.

En ese sentido, se suele sostener que el encéfalo es un sistema clásico causalista que obedece a leyes deterministas. Hasta ahora no se ha presentado ningún experimento que muestre signos inequívocos de

\footnotetext{
${ }^{6}$ MARAIS, A. et al.; “The future of quantum biology”, J. R. Soc. Interface, Vol. 15, N. 148, 2018.

${ }^{7}$ Un nanómetro es la mil millonésima parte de un metro, expresado como $1 \times 10^{-9}$ metros.

${ }^{8}$ ADAMS, B. y PETRUCCIONE, F.; "Quantum effects in the brain: A review”, AVS Quantum Science, Vol. 2. N.2, 2020.
} 
efectos cuánticos en el cerebro, además de la falta de plausibilidad científica de que pueda ser así. ${ }^{9}$ Pero, antes de abordar esta discusión, vale la pena cuestionarse, ¿realmente qué implica la mecánica cuántica frente al determinismo?

En la mecánica cuántica, operante en escalas tan pequeñas donde los efectos cuánticos están presentes, la repetición de un experimento bajo condiciones idénticas no garantiza idénticos resultados. ${ }^{10}$ En otras palabras, a escalas nanométricas el determinismo parece ser falso.

Esto obedece, en primer lugar, a la dualidad onda-partícula de la materia propuesta por el físico LouisVictor de Broglie, ${ }^{11}$ y bajo la interpretación de Copenhague, implica que solo hay un catálogo probabilístico para diferentes cantidades como la posición, la energía o el momento lineal considerando todos sus posibles valores. ${ }^{12}$ En segundo lugar, el principio de incertidumbre implica que no podemos medir la posición y el momento de una partícula con absoluta precisión; cuanto más exactamente conocemos uno de estos valores, menos exactamente conocemos el otro. ${ }^{13}$ En tercer lugar, el problema de la medida implica que no se pueden conocer las propiedades del sistema sino hasta medirlas; antes de esto, solo podemos referirnos a la superposición, es decir, a que existe en todos sus estados posibles; solo con la medida se adquiere un estado determinado.

Partiendo de estos conceptos, bien lo expresa Muñoz, al visualizar el impacto de la mecánica cuántica sobre el determinismo: “¿Cómo podemos confiar en las leyes de la naturaleza como actor fundamental para alcanzar un solo futuro posible en cada instante de tiempo si existen leyes físicas cuya esencia es la impredecibilidad?". ${ }^{14}$ La mecánica cuántica es una teoría probabilística, lo que implica que el determinismo, como teoría que gobierna de manera absoluta el universo, podría ser falsa.

Como se había discutido al principio de este apartado, los efectos cuánticos, por lo general, solo son apreciables o perceptibles en escalas nanométricas por lo que en principio se suele rechazar cualquier

\footnotetext{
${ }^{9}$ SÁNCHEZ-CAÑIZARES, J.; “¿Es relevante la mecánica cuántica para la comprensión científica del problema mente-cerebro?”, en 60 preguntas sobre ciencia y fe respondidas por 26 profesores de universidad, Madrid, Editorial Stella Maris, 2014.

${ }_{10}$ MUÑOZ, J.; “Mecánica Cuántica y Libre Albedrío: Cinco Cuestiones Fundamentales”, Principia: An International Journal of Epistemology, Vol, 19 N,1, 65, 2015.

${ }^{11}$ DE BROGLIE, L.; "Recherches sur la théorie des quanta”, Paris, Annales De Physique III, 1925.

12 VANNEY, C.; "Interpretaciones de la mecánica cuántica", Diccionario Interdisciplinar Austral, 2016.

${ }^{13}$ EASTWOOD, M.; “Heisenberg's uncertainty principle”, QJM: An International Journal of Medicine, Vol.110, N.5, 2017, pp 335-336.

${ }^{14}$ Ibid. MUÑOZ, J 2015. p.72.
} 
influencia en sistemas macro como el encéfalo y el cuerpo humano. Sin embargo, múltiples hipótesis se han planteado sobre los efectos cuánticos en sistemas biológicos macroscópicos.

Quizás el primero en proponer la injerencia de los efectos cuánticos en el cerebro fue el Nobel de Física, Roger Penrose. En su libro La nueva mente del emperador, Penrose sugiere la necesidad de estudiar la mecánica cuántica como complementaria para entender el encéfalo humano. ${ }^{15}$ Posteriormente, junto con el anestesiólogo y psicólogo Stuart Hameroff, proponen formalmente que dentro de las neuronas del cerebro puede haber pequeñísimas estructuras que permitan la manifestación de los efectos cuánticos. ${ }^{16}$ Otras propuestas de la injerencia de efectos cuánticos en el encéfalo y en el comportamiento humano se encuentran revisados en el artículo de Adams y Petruccione ${ }^{17}$ aunque aún no es posible afirmar inequívocamente que la indeterminación se manifiesta en escalas macroscópicas.

\section{Compatibilismo e incompatibilismo}

El problema tradicional del libre albedrío fue resolver la cuestión sobre si el determinismo era verdad, por lo que no podríamos tener libre albedrío. La discusión solía ser la certeza sobre el determinismo, la posesión de poderes contra-causales voluntarios del ser humano para ser su propia causa, causa sui, y afirmar, o negar, la doctrina del libre albedrío. Sin embargo, el debate ya no se ha centrado en si el determinismo causalista es verdad, pues a la luz de la ciencia moderna es algo que debe tomarse en serio. El problema actual del libre albedrío es si éste es compatible con el determinismo; incluso, bajo los paradigmas contemporáneos de la física cuántica, también deberíamos preguntarnos si es compatible con el indeterminismo.

En otras palabras, si el comportamiento humano obedece a factores neurobiológicos y ambientales, ambos acontecidos en nuestro universo material regido por leyes naturales descritas, y por describir, por la ciencia, la discusión ya no puede ser negar la ciencia; la nueva discusión es si lo que nos dice es compatible frente a nuestra noción de lo que es el libre albedrío.

\footnotetext{
15 PENROSE, R.; The Emperor's New Mind: Concerning Computers, Minds, and the Laws of Physics, Nueva York, Oxford University, 1989.

${ }^{16}$ HAMEROFF, S. y PENROSE, R.; "Orchestrated reduction of quantum coherence in brain microtubules: A model for consciousness", Mathematics and Computers in Simulation, Vol.40, 3-4, 1996.

${ }^{17}$ ADAMS, B. y PETRUCCIONE, F.; "Quantum effects in the brain: A review”, AVS Quantum Science, Vol. 2. N.2, 2020.
} 
Los orígenes de este nuevo problema se remontan hacia 1884, cuando el psicólogo y filósofo estadounidense William James propone el concepto de determinismo "soft" y "hard", conceptos que serían los antecedentes del actual compatibilismo e incompatibilismo. ${ }^{18}$

Pero no sería sino hasta 1983 cuando el filósofo Peter van Inwagen propuso en su reconocido Ensayo sobre el Libre Albedrío una nueva terminología: el compatibilismo y el incompatibilismo. La obra de van Inwagen es clara al plantear que "la principal cuestión controvertida en las discusiones actuales sobre el libre albedrío no es, como cabría esperar, si tenemos libre albedrío; es si el libre albedrío es compatible con el determinismo". ${ }^{19}$ En general, la tesis del incompatibilismo se presenta mediante el argumento consecuencial que sostiene que si el determinismo es verdad; el libre albedrío no existe pues las acciones obedecen al pasado remoto y a las leyes de la naturaleza, ambas sobre las que no tenemos control. Por lo tanto, las consecuencias de las acciones no dependen realmente de nosotros. ${ }^{20}$

Ahora bien, dentro del incompatibilismo existe una corriente minoritaria llamada libertarismo, que es la tesis que sostiene la incompatibilidad del libre albedrío frente al determinismo, pero opta por negar el determinismo al plantear que es falso y que los seres humanos no están sujetos a las leyes deterministas de la física. Para no quedar rezagados en el debate, los más cuerdos libertaristas defienden el libre albedrío a través del indeterminismo de la mecánica cuántica. Sin embargo, este argumento ha sido ampliamente refutado, pues del azar no se desprende ningún tipo de control último ni libertad real. ${ }^{21}$

El incompatibilista Derk Pereboom ve al libre albedrío y a la responsabilidad moral como incompatibles tanto con el determinismo como con el indeterminismo:

"Según lo veo, actualmente es una cuestión abierta si es verdadera la interpretación indeterminista o determinista de la mecánica cuántica. Sin embargo, sostengo que no solo el determinismo es incompatible con la responsabilidad moral, sino también el tipo de indeterminación especificado por la interpretación estándar de la mecánica cuántica, si ese es el único tipo de indeterminación que existe. Además, sostengo que no tenemos evidencia de indeterminación del tipo que se

\footnotetext{
18 JAMES, W.; "The dilemma of determinism", en: The Will to Believe: And Other Essays in Popular Philosophy, Cambridge, Cambridge University Press, 2014, p.149.

${ }^{19}$ VAN INWAGEN, P.; An Essay on Free Will, Oxford, Clarendon Press, 1983, p.55.

${ }^{20}$ Ibid. VAN INWAGEN, 1983.

${ }^{21}$ SMART, J. y HALDANE, J.; Atheism and Theism, Malden, Blackwell Publishing Ltd, 2003.
} 
requeriría para el libertarismo agente-causal ${ }^{22}$ y que, por lo tanto, no tenemos evidencia de que seamos moralmente responsables". ${ }^{23}$

En ese sentido, rechazamos el libertarismo y acogemos la definición del incompatibilismo duro: el libre albedrío es incompatible tanto con el determinismo como con el indeterminismo. El azar, entonces, no puede rescatar al libre albedrío pues cualquier acción incausada e indeterminada no es producto real de la autoría y el control del individuo; es el simple resultado de la aleatoriedad.

Por su parte, el compatibilismo es la postura que sostiene que el libre albedrío es perfectamente compatible con el determinismo. Sin embargo, una de las grandes críticas en contra del compatibilismo es que, en lugar de dar una defensa real del libre albedrío, cambia su concepto, aceptando en ocasiones que es una ilusión, y sosteniendo un libre albedrío mucho más simple: el no ser obligado por fuerzas externas a hacer algo. El filósofo John Locke es quizás uno de sus más importantes precursores pues no se pregunta si la voluntad es libre, sino si el hombre es libre de actuar. Ello se encuentra magistralmente expuesto el Ensayo sobre el entendimiento humano. Afirma que, con respecto al acto de querer, no habría libertad. Antes de cualquier voluntad hay una precedente que la determina y así al infinito. ${ }^{24}$ La libertad sería la libertad de ejecutar lo que se quiere, aunque no haya libertad en el querer o no querer. ${ }^{25}$

Samuel Harris, uno de los autores incompatibilistas más reconocidos en países angloparlantes, resume la crítica principal en contra del compatibilismo de la siguiente forma:

"El "libre albedrío" que defienden los compatibilistas no es el libre albedrío que la mayoría de la gente siente que tiene. Los compatibilistas generalmente afirman que una persona es libre siempre que esté libre de cualquier compulsión externa o interna que le impida actuar de acuerdo con sus deseos e intenciones reales. Si desea una segunda cucharada de helado y nadie le obliga a comerlo, comer una segunda cucharada es una demostración total de su libre albedrío. La verdad, sin embargo, es que las personas reclaman una mayor autonomía que esta. Nuestras intuiciones

\footnotetext{
${ }^{22}$ Según lo entiende Pereboom, «En el libertarismo agente-causal, el libre albedrío se explica por la existencia de agentes que pueden causar acciones no en virtud de cualquier estado en el que se encuentren, como una creencia o un deseo, sino simplemente por sí mismos, como sustancias» (xv). Como se aborda en este texto, consideramos la imposibilidad de que una persona, como ser biológico material, sea causa sui, o su propia causa.

${ }^{23}$ PEREBOOM, D.; Living Without Free Will, Cambridge, Cambridge University Press, 2003, xviii.

${ }^{24}$ LOCKE, J.; An Essay Concerning Human Understanding, Pensilvania, The Pennsylvania State University, 1999, p. 230 , pár. 23.

${ }^{25}$ Ibid. LOCKE, 1999. pp.230-231, párrs.23-24.
} 
morales y nuestro sentido de agencia personal están anclados a una sensación sentida de que somos la fuente consciente de nuestros pensamientos y acciones". ${ }^{26}$

En su concepto, entonces, el compatibilismo no es más que una afirmación del siguiente credo: un títere es libre mientras ame sus hilos. ${ }^{27}$ En cierto sentido, los compatibilistas suelen confirmar el libre albedrío si la persona puede hacer lo que quiere hacer, mas no se cuestionan si puede querer lo que quiere; si es autor final, o si está siquiera en control último de lo que quiere hacer o el porqué.

El compatibilismo contemporáneo es un poco más desarrollado al repensar el libre albedrío como la capacidad de la persona para controlar su conducta sobre la base de consideraciones racionales; la armonía en el funcionamiento de la estructura psíquica de un agente; la sensibilidad del agente en las razones en la producción de una acción, o plantear cierta libertad de margen. ${ }^{28}$ Sin embargo, como estas teorías acogen el determinismo, al final ignoran el hecho de que el agente no estaba en verdadero control último, ni podía ser autor, de las causas precedentes que construyen la racionalidad de sus acciones o que conducen a un desarrollo determinado de su encéfalo; que causan su comportamiento de determinada manera. En lugar de defender el concepto tradicional de libre albedrío como la habilidad de poder actuar de manera distinta, de ser autor final, o causa sui, los compatibilistas redefinen su noción de libre albedrío, para igualarla a la de capacidad de razonar, o a la integridad de la estructura neurológica, o el planteamiento de hipótesis alternativas, que, a la luz del determinismo, eran imposibles.

\section{La neurociencia: un nuevo problema para el derecho penal}

Los grandes desarrollos desde las escuelas clásicas, neoclásicas, finalistas y funcionalistas han conducido a definir el delito como una conducta típica, antijurídica y culpable. Una conducta que reviste características de delito deberá cumplir descripciones objetivas, pero también unos requisitos subjetivos, que son, precisamente, los que más nos importan.

La relación entre neurociencia y derecho penal no ha sido del todo cordial. Por lo menos desde 1983, la neurociencia amenaza con destruir gran parte de las construcciones dogmáticas del derecho penal. Conceptos como el de dolo, culpa, preterintención, capacidad de comprender la ilicitud o de

\footnotetext{
${ }^{26}$ HARRIS, S.; Free will, Nueva York, Simon \& Schuster, 2012, p.8.

${ }^{27}$ Ibid: HARRIS, S.; Free will, 2012.

${ }^{28}$ MCKENNA, M. y PEREBOOM, D.; Free Will. A Contemporary Introduction, Nueva York, Routledge, 2016.
} 
autodeterminarse, se encuentran en la cuerda floja en razón a lo que la neurociencia está descubriendo sobre el comportamiento humano; sobre todo aquellas discusiones en torno al principio de culpabilidad. Tanto es así, que el profesor Winfried Hassemer (QEPD) escribió hace más de una década que:

"Las consecuencias de la discusión de biología humana para la justicia penal son evidentes. Lo único que cabe aconsejarle es eludir, en una maniobra evasiva a gran distancia, esta discusión. Si permite que se la mezcle en ella, éste será el fin de su trabajo. No hay elección: su problema es estructural, y no puede resolverse con buena voluntad y apertura al mundo". ${ }^{29}$

En ese sentido, es relevante conocer qué investigaciones se han realizado y qué reflexiones han brindado. El problema inicia con las investigaciones del neurólogo estadounidense Benjamin Libet, quien fue pionero en indagar sobre la actividad eléctrica que antecede a la consciencia de una acción, denominada potenciales pre-motores o "readiness potentials". En su experimento, encontró una actividad eléctrica que antecede a la consciencia por 350 milisegundos aproximadamente. La conclusión de Libet, sobre la presencia de estos potenciales, es que los procesos cerebrales de actos voluntarios inician de manera inconsciente en nuestros cerebros y la consciencia de haber tomado una decisión vendría a ser un resultado posterior. ${ }^{30}$

A partir de las investigaciones de Libet, múltiples científicos continuaron abordando el proceso de toma de decisiones con experimentos similares. Así, por ejemplo, en 1999 Patrick Haggard y Martin Eimer presentaron una investigación, abordando los potenciales neuronales y la conciencia temporal de movimientos voluntarios. En sus palabras, estos experimentos son importantes pues plantean serios debates lógicos y filosóficos al posiblemente señalar que "mi cerebro parece saber que me voy a mover antes de que yo lo sepa". ${ }^{31}$ Las conclusiones de su investigación comprueban la existencia de actividad eléctrica, que ellos denominan como "Lateralised Readiness Potential” (LRP), y que precede a los actos libres y a la conciencia de querer ejecutarlos.

En el año 2008, Soon y su equipo, publicaron el artículo "unconscious determinants of free decisions in the human brain". En dicha investigación se emplearon las técnicas de resonancia magnética funcional

\footnotetext{
${ }^{29}$ HASSEMER, W.; "Neurociencias y culpabilidad en Derecho penal”, InDret V2., 2011, p.3.

${ }^{30}$ LIBET, B. et al.; "Time of conscious intention to act in relation to onset of cerebral activity (readiness-potential). The unconscious initiation of a freely voluntary act”, Brain: a journal of neurology, Vol.106, 3, 1983.

${ }^{31}$ HAGGARD, P. y EIMER, M.; "On the relation between brain potentials and the awareness of voluntary movements", Experimental Brain Research, Vol.126, 1999, p. 128.
} 
para analizar qué regiones del cerebro predeterminan las intenciones conscientes y el momento en que comienzan a dar forma a decisiones motoras. La conclusión a la cual llegaron es que el resultado de una decisión puede codificarse en la actividad cerebral de la corteza prefrontal y parietal hasta 10 segundos antes de que entre en la conciencia. ${ }^{32}$ En el año 2013, encontraron evidencia de que decisiones más complejas también pueden predecirse. Logrando anticipar el resultado de decidir sumar o restar números hasta 4 segundos antes de la consciencia de esta decisión; demostrando que la preparación inconsciente de las elecciones no se restringe al movimiento, sino que puede extrapolarse a intenciones complejas y múltiples escalas de abstracción. ${ }^{33}$

Lo cierto es que los avances en las neurociencias nos están guiando a plantear que el libre albedrío y la conciencia no son más que un espejismo; una ilusión que crea nuestro encéfalo para centrarse en información y darle una explicación social plausible a decisiones y acciones que provienen de procesos automáticos sobre los cuales no hay control último. Estos procesos obedecen a hechos físicos, químicos y eléctricos automáticos. En otras palabras, la conciencia e incluso el sentimiento mismo del yo que controla no es más que un maravilloso e intrigante proceso del cerebro.

Estas conclusiones, ni más faltaba, siguen siendo objeto de controversia. Incluso el mismo Libet, a pesar de sus hallazgos, seguía creyendo en el libre albedrío. Trevena y Miller, por su parte, argumentaron que los hallazgos de Libet no lograban demostrar que el movimiento voluntario iniciaba inconscientemente. ${ }^{34}$ Guggisberg et al, ${ }^{35}$ Glannon, ${ }^{36}$ y Mele $^{37}$ argumentan también en contra de la metodología y las conclusiones de estos experimentos. Sin embargo, consideramos que se ignora el debate real de que las neurociencias y la física nos señalan que nuestro encéfalo material sigue siendo un órgano automático, que, junto con el cuerpo biológico, funcionan en interacción con un ambiente, y ambos factores son deterministas (o poco probable; indeterministas). Todo acto humano e incluso el sentimiento personal de

\footnotetext{
32 SOON, C. et al.; "Unconscious determinants of free decisions in the human brain", Nat Neurosci, V.11, 5, 2008.

${ }^{33}$ SOON, C. et al.; "Predicting free choices for abstract intentions", Proceedings of the National Academy of Sciences of the United States of America, 110, 15, 2013.

34 TREVENA J, y MILLER J.; Brain preparation before a voluntary action: evidence against unconscious movement initiation. Conscious Cogn., 19(1), 2010.

${ }^{35}$ GUGGISBERG A, et al.; Timing and awareness of movement decisions: does consciousness really come too late? Front Hum Neurosci., 7:385, 2013.

${ }^{36}$ GLANNON, W.; Brain, Body, and Mind: Neuroethics with a Human Face, Oxford, Oxford Scholarship Online, 2011.

${ }^{37}$ MELE, A.; Free: Why Science Hasn't Disproved Free Will, Oxford, Oxford University Press, 2014.
} 
agencia del yo que comanda el cuerpo material, siguen siendo fenómenos provenientes de la actividad neuronal en un entorno igualmente determinado por las leyes de la naturaleza y el pasado remoto.

Es necesario reconocer que los experimentos actuales de la neurociencia, por sí solos, no demuestran la inexistencia metafísica del libre albedrío, pero sí sientan las bases para el debate, junto con una interpretación sistemática de todas las ciencias en su conjunto, incluyendo la física, pero también ciencias sociales como la sociología que apunta a cómo los hechos sociales determinan al ser humano, en el debate estructura vs. agencia.

Retomando el debate sobre la neurociencia, esto representa un gran problema para el derecho penal. En primer lugar, porque varias de las construcciones de la teoría del delito, como el dolo, que implican conceptos como intención o voluntad y el conocimiento de los hechos, parten de premisas refutables por la ciencia. Una conducta no puede considerarse realmente voluntaria si su origen proviene de procesos físicos, químicos y eléctricos automáticos, inconscientes e indisponibles para el sujeto; sobre los cuales no era verdadero autor, no conocía y no controlaba.

En segundo lugar, el derecho penal enfrenta un reto mayúsculo pues uno de sus principios fundamentales, la culpabilidad, no tiene sentido en un universo físicamente determinista, donde, además, la neurociencia aporta nuevos argumentos en contra del libre albedrío. El principio de culpabilidad implica el juicio de reproche que se le hace a quien, pudiendo actuar conforme al derecho, decide libre y conscientemente actuar en contra. Así las cosas, "no hay pena sin culpabilidad, pues la sanción criminal sólo debe fundarse en la seguridad de que el hecho puede serle exigido al agente". ${ }^{38}$ La culpabilidad es, entonces, el fundamento de la pena. ${ }^{39}$ Esto se basa en que el autor pudo haber actuado de manera distinta, al considerar al hombre como un ser libre que tiene capacidad de autodeterminación o libre albedrío. ${ }^{40}$ Para el profesor Claus Roxin, “existe por tanto acuerdo en que el derecho penal debe partir del libre albedrío, aunque el mismo no se pueda demostrar exactamente". ${ }^{4}$

\footnotetext{
${ }^{38}$ BALMACEDA, G.; Estudios de Derecho Penal General: una aproximación a la teoría del delito y de la pena, Bogotá, Ediciones Nueva Jurídica y Universidad de la Sabana, 2015, p.291.

${ }^{39}$ CÓRDOBA, M.; “Culpabilidad”, en: Lecciones de Derecho Penal Parte General, Bogotá, Universidad Externado de Colombia, 2011.

${ }^{40}$ Ibid. BALMACEDA, 2015.

${ }^{41}$ ROXIN, C.; Derecho Penal parte general, Tomo I: Fundamentos, la estructura de la teoría del delito, Madrid, Civitas, 1997, p.809.
} 
Sin embargo, en un universo determinista, donde el comportamiento humano obedece a procesos físicos, químicos y eléctricos automáticos e indisponibles para el sujeto, en interacción con un ambiente también material y determinista, está claro que nada puede suceder de manera distinta a como lo hace. Por otra parte, si se aceptara el indeterminismo cuántico, sí sería posible la existencia de alternativas, mas no producto de una decisión del sujeto, sino por mera aleatoriedad de las leyes indeterministas de la mecánica cuántica. La culpabilidad, como principio fundamental del derecho penal, ha sido destruido.

El reconocido jurista español, Enrique Gimbernat Ordeig, ya lo auguraba hace más de medio siglo, cuando publicó un capítulo titulado ¿Tiene un futuro la dogmática jurídicopenal? Su disertación giraba en torno a las consecuencias de la inexistencia del libre albedrío y al siguiente efecto dominó: "la crisis de la idea de la culpabilidad trae consigo la de la pena; y sin pena no puede haber derecho penal, y sin éste tampoco una ciencia del derecho penal en sentido tradicional" ${ }^{42}$ El derecho penal, entonces, está en la cuerda floja. Sin culpabilidad el derecho penal solo puede resignificar sus principios fundamentales para sobrevivir, o, por el contrario, ser abolido en una transición a largo plazo, tesis que sostenemos como necesaria.

A pesar de que el profesor Gimbernat Ordeig realizó varias aproximaciones para salvar al derecho penal frente a la inexistencia del libre albedrío, es de resaltar lo siguiente:

"Pretender fundar el derecho penal en el indemostrable libre albedrío es, pues, una batalla perdida de antemano; librarla, a pesar de todo, solo puede tener como resultado aumentar la irritación de los científicos empíricos; pues es simplemente una provocación que los juristas, en estas materias en las que no son especialistas, pretenden darles lecciones a los que sí lo son, o rechazar cualquier clase de diálogo con ellos, decidiéndose "irracionalmente" a favor del libre albedrío". ${ }^{3}$

\section{El compatibilismo humanista}

En el año 2013, el profesor español Eduardo Demetrio Crespo publicó un capítulo titulado “compatibilismo humanista": Una propuesta de conciliación entre Neurociencias y Derecho Penal”. En dicha obra propone:

\footnotetext{
42 GIMBERNAT, E.; “¿Tiene un futuro la dogmática jurídicopenal?”, en: Problemas actuales de Derecho penal y procesal, Salamanca, Universidad de Salamanca, 1971, p.88.

${ }^{43}$ Ibid. GIMBERNAT, 1971, p.90.
} 
[...] "una solución conciliadora entre las ciencias biológicas, en particular las Neurociencias, y el Derecho penal sobre la base de un "compatibilismo humanista". "Compatibilismo", porque parte de la compatibilidad o el entendimiento entre ciencias empíricas (y biológicas) y Derecho, particularmente el Derecho Penal. "Humanista", porque reposa y encuentra su única razón de ser en la dignidad del ser humano". ${ }^{4}$

El profesor Demetrio Crespo adopta en su propuesta un concepto mínimo de libertad, compatible con el determinismo. En ese sentido, se promueve el concepto de autodeterminación, que parte de dos presupuestos: autonomía y autoría. Autonomía significaría precisamente un acto libre, no coaccionado; autoría implicaría que el acto ejecutado por un autor racional, sin patologías, obedece a sus preferencias (deseos, disposiciones, creencias y emociones) y por lo tanto se entiende como un acto de su autoría. Por otra parte, reconoce que el concepto fuerte y tradicional de libre albedrío como "poder actuar de otro modo", es un concepto con el que el derecho penal no puede trabajar, ergo, el concepto mínimo de libertad sería suficiente para conciliar el aparente conflicto entre neurociencia y derecho penal, permitiéndole al segundo continuar existiendo.

Sobre este punto es importante hacer hincapié que este concepto mínimo de libertad adoptado en la propuesta es propio del compatibilismo pues reconoce la necesidad de modificar el concepto tradicional del libre albedrío del poder o habilidad de actuar de forma distinta, al de una libertad limitada de hacer lo que uno quiere hacer sin impedimento. ${ }^{45}$ Sin embargo, esta visión es defectuosa. Por un lado, dada la verdad del determinismo, en el momento en que una persona actuó, no podría haber tenido más deseos que los deseos que su historia causal determinó que tuviera. Por otra parte, el hecho de que tengamos preferencias y actuemos de acuerdo con tales disposiciones, no nos convierte en agentes responsables, ya que es evidente que las leyes que gobiernan dichas preferencias son deterministas.

En otras palabras, aun cuando actuemos bajo nuestros deseos o preferencias, no somos autores, ni estamos en control de dichas preferencias pues estas tienen orígenes en los factores neurobiológicos (genes, estructura y funcionamiento cerebral) y ambientales (cultura, sociedad etc.); factores sobre los cuales no tuvimos elección, por lo que no podemos ser moral y penalmente responsables.

\footnotetext{
${ }^{44}$ DEMETRIO, E.; "Compatibilismo humanista: una propuesta de conciliación entre neurociencias y derecho penal”, en Neurociencias y derecho penal: nuevas perspectivas en el ámbito de la culpabilidad y tratamiento jurídico-penal de la peligrosidad, Madrid, Edisofer S.L, 2013, p.39.

${ }^{45}$ MCKENNA, M. y PEREBOOM, D.; Free Will. A Contemporary Introduction, Nueva York, Routledge, 2016.
} 
Si los factores neurobiológicos y ambientales que produjeron nuestra conducta son factores deterministas, el principio de culpabilidad penal no puede seguir sosteniéndose pues no podíamos actuar de manera distinta. Lo anterior porque esencialmente no hay nada que se pueda reprochar sin reprochar de antemano todas las causas precedentes desde la creación del espacio y tiempo, tesis que a todas luces sería absurda. No se diga de lo defectuoso que sería asumir la discusión desde el indeterminismo. Bajo esta óptica los deseos y preferencias de la persona no pueden siquiera atribuirse a sí mismo tan solo por tener origen en su encéfalo ${ }^{46}$, pues los deseos o preferencias serían mero producto de la aleatoriedad y ni siquiera serían coherentes con el pasado o la personalidad del sujeto.

Retomando la obra del profesor Demetrio Crespo, se presenta el compatibilismo como una forma razonable de conciliar el problema creado por las interpretaciones de la neurociencia en contra del derecho penal de la culpabilidad. Sobre el compatibilismo, tal como lo expresa en su obra, "puede verse tal vez como una "solución de compromiso". ${ }^{47}$ Esto implicaría, entonces, hacer un leve sacrificio al concepto duro de libre albedrío y aceptar cierto determinismo relativo, pero, a cambio, el derecho penal podría seguir existiendo.

Más adelante, la obra revela quizás la gran razón de peso para sostener una propuesta compatibilista. Sostener las tesis del determinismo duro, y con ello del incompatibilismo, representa un grave riesgo de llegar a un derecho penal totalitarista y peligrosista, fundado en las medidas de seguridad y la responsabilidad objetiva. Es por eso que encontramos razonable la preocupación, la compartimos, pero discrepamos en que ese sea el único resultado posible de la negación del libre albedrío. La abolición es la verdadera alternativa humanista.

\section{El incompatibilismo humanista: una contrapropuesta del neuroabolicionismo penal}

Ponemos sobre la mesa una contrapropuesta al compatibilismo humanista. Encontramos en el incompatibilismo duro una postura prometedora como base para avanzar hacia la abolición del dolor

\footnotetext{
${ }^{46}$ En este punto conviene también precisar que, contrario a lo que advierte el profesor Demetrio Crespo, no creemos que la falacia mereológica sea una verdadera falacia; o por lo menos no como se suele abordar, discusión que se ha estudiado profundamente en la filosofía de la mente. Como cualquier otro órgano, el encéfalo cumple una serie de funciones que dan origen al comportamiento humano. Por supuesto sería un error retrotraerse a una forma de dualismo encéfalo-sujeto, pero las descripciones sobre el encéfalo favorecen la posibilidad de describir científicamente la forma como las partes de un animal o ser humano dan origen a su conducta. Como punto de partida, puede consultarse a SMIT, H. y HACKER, P.; "Seven Misconceptions About the Mereological Fallacy: A Compilation for the Perplexed", Erkenn, 79, 2014

${ }^{47}$ DEMETRIO, E.; “Compatibilismo humanista: una propuesta de conciliación entre neurociencias y derecho penal” (...), pp.28-29.
} 
estéril e injustificado que representa el derecho penal. Esta postura de la filosofía de las ciencias y del derecho, debe afirmar que, en un universo determinista o indeterminista, el libre albedrío es un concepto que debe perecer. Con ello, al igual que un efecto dominó, la responsabilidad moral y penal no puede seguir sosteniéndose para reprochar conductas humanas.

Esta es una propuesta coherente con los avances de las ciencias naturales, especialmente la física y la neurociencia. Encontramos en la neurociencia la clave del comportamiento humano, la verdadera cuestión que nos conduce a afirmar la inexistencia del libre albedrío. No solo por el hecho innegable de que nuestro encéfalo está hecho de materia sujeta a leyes de la naturaleza descritas por la ciencia. La neurociencia nos introduce al verdadero estudio científico del comportamiento humano al comprender los factores neurobiológicos y ambientales que cumplen sus roles causales en nuestra conducta. Las neurotecnologías, por su parte, han permitido observar y producir importantes reflexiones sobre los procesos físicos, químicos y eléctricos automáticos que constituyen la compleja red de miles de millones de neuronas y células gliales en nuestro cerebro.

Ahora bien, consideramos relevante asumir también el humanismo como límite a cualquier desarrollo en la justicia, la ciencia y las tecnologías. El humanismo resalta la importancia de los derechos humanos y la dignidad humana, al afirmar cualidades humanas que son inalienables. La existencia o no del libre albedrío no es relevante al afirmar el valor intrínseco de un ser humano. Comprender lo que la física o la neurociencia nos explica sobre la naturaleza humana jamás será óbice para reconocer el valor de nuestra existencia y de lo que como sociedad hemos construido. El valor de un ser humano que siente, piensa, ama y sufre, no depende de la comprobación o refutación del libre albedrío y por ello no se debe admitir la instrumentalización o cosificación de la persona. Una verdadera postura humanista debe, por consiguiente, propender por la reducción del sufrimiento humano y la promoción de su bienestar general. El paso inicial es, entonces, el tránsito hacia el abolicionismo penal y la cultura restaurativa.

El derecho penal, con sus teorías relativas de la pena, utiliza al individuo con fines disuasorios para mostrar el dolor que le es causado ante sus conciudadanos y esperar, por parte de estos, docilidad. Ese mismo derecho penal, con sus teorías absolutas, crea una narrativa para sostener que la pena es justa porque retribuye, o porque se sostiene que dicha imposición de dolor es un imperativo categórico.

Es por eso que, fiel a una visión humanista, asumimos una postura incompatibilista para fundar una propuesta complementaria al abolicionismo europeo sociológico: el neuroabolicionismo penal. Los 
abolicionistas clásicos como Nils Christie, Thomas Mathiesen o Louk Hulsman, denunciaron desde la sociología la ilegitimidad del derecho penal.

El derecho penal, el de la vida real fuera de los textos dogmáticos, en primer lugar, se edifica mediante una política criminal del dolor. El sociólogo noruego Nils Christie, exponía que el castigo, tal como lo imponen los códigos penales, es la imposición consciente de dolor. Sin embargo, el dolor que se impone mediante el sistema penal es uno exacerbado, en expansión, cuya finalidad estéril es lograr el sufrimiento de quien la padece y simplificar el problema pues culpa al individuo, mas no al sistema social. En síntesis, infligimos dolor, dolor deliberado, dolor estéril, y lo hacemos con la conciencia tranquila. Es por eso que, de acuerdo con Christie:

[...] "los sistemas sociales deberían construirse de manera que redujeran al mínimo la necesidad percibida de imponer dolor para lograr el control social. La aflicción es inevitable, pero no lo es el infierno creado por el hombre". ${ }^{48}$

Un segundo hecho sobre el derecho penal es que se construye a partir de políticas criminales irracionales y reactivas. Es decir, la creación legislativa de la política penal obedece más a fenómenos de opinión pública que a verdaderos estudios criminológicos. Siguiendo al Profesor Raúl Carnevali “el derecho penal es prima ratio, esto es, se emplea el recurso punitivo para prevenir ciertos comportamientos sin examinar siquiera cuan eficiente y necesario pueda ser este". 49

Un tercer elemento del derecho penal es su carácter selectivo. Esto quiere decir que el poder punitivo del Estado históricamente castiga a ciertos grupos, especialmente, grupos de personas vulnerables. En Colombia, por ejemplo, de acuerdo con el Instituto Nacional Penitenciario y Carcelario el 96,3 \% de la población privada de su libertad es iletrada, cursó primaria o se graduó sólo de bachillerato; tan sólo un $1 \%$ tiene formación profesional universitaria de nivel pregrado. ${ }^{50} \mathrm{El}$ sociólogo Loïc Wacquant acierta al sostener que las cárceles son depósitos a donde la sociedad envía a los pobres y a quienes considera indeseables. ${ }^{51}$ Así pues, enviando a los grupos marginales a las cárceles y penitenciarías, el Estado se lava las manos al enviar un mensaje simbólico vacío, pero dejando intactas las estructuras sociales que

\footnotetext{
${ }^{48}$ CHRISTIE, N.; Los límites del dolor, Ciudad de México, Fondo de Cultura Económica, 1998, p.15.

${ }^{49}$ CARNEVALI, Raúl.; “Derecho penal como ultima ratio. Hacia una política criminal racional”, Ius et Praxis, Vol. 14, n.1, 2008 , p.31.

${ }^{50}$ INPEC.; Tableros Estadísticos: Nivel académico Intramural, Bogotá, INPEC, 2020.

${ }^{51}$ WACQUANT, L.; Las cárceles de la miseria, Buenos Aires, Manantial, 2000.
} 
condujeron a una persona a dar el paso hacia un acto que infringía la ley penal; en aquellos casos donde se identifican factores criminógenos individuales, el Estado ni siquiera es capaz de prestar un servicio de salud física y mental integral para los infractores.

Por otra parte, es posible denunciar hechos como las políticas estigmatizantes que construye el derecho penal, el papel que juegan los medios de comunicación, la industria de la prisión, la falacia de la resocialización en las prisiones y demás. Sin embargo, es sustancial, por ahora, entender que el derecho penal no es una amarga necesidad; no es algo que deba existir. El delito es una construcción social; así como se construye puede ser destruido. Siguiendo las palabras de Christie:

"El delito no es una "cosa". Es un concepto aplicable en ciertas situaciones sociales donde es posible cometerlo y cuando a una o varias partes les interesa que se aplique. Podemos crear el delito creando sistemas que requieran esa palabra. Podemos extinguirlo creando los tipos opuestos de sistemas". 52

Si bien los abolicionistas europeos construyeron un cuerpo sólido de teorías que denuncian la ilegitimidad moral, social, política y práctica del derecho penal, es posible argumentar que sus posturas sociológicas pueden y deben ser complementadas. El abolicionismo sociológico parte de una teoría criminológica que podría pensarse como incompleta: la criminología crítica. Este enfoque entiende el delito exclusivamente como un problema social y comunitario, sin embargo, el delito es también un problema individual. Lo anterior no porque el delito exista como ente en el universo y exista la delincuencia por naturaleza o los individuos criminales. Los conflictos o situaciones problemáticas también son un problema individual pues son las conductas de los individuos implicados las que se deben estudiar, no sólo los hechos sociales. Entender la desviación individualmente considerada es también fundamental para proponer una tesis abolicionista que comprenda de manera holística las circunstancias, las causas y los factores de riesgo que guían a una persona a dar el paso hacia un acto que lesiona los bienes, derechos e intereses de otra persona.

Por esta razón, proponemos el surgimiento del neuroabolicionismo penal como una propuesta complementaria al abolicionismo europeo de corte sociológico. Consideramos que las ciencias naturales y de la salud mental pueden aportar significativos argumentos en favor de la propuesta del abolicionismo

52 CHRISTIE, N.; Los límites del dolor, Ciudad de México, Fondo de Cultura Económica, 1998, p.101. 
penal. Para la construcción de este nuevo planteamiento, proponemos los siguientes postulados básicos, cuyo desarrollo será objeto de un trabajo futuro:

\subsection{Sin libre albedrío no puede existir el derecho penal de la culpabilidad}

Las bases para refutar el libre albedrío fueron desarrolladas en las partes iniciales de este texto. Sostenemos, por consiguiente, que al negar el libre albedrío y adscribirse al incompatibilismo humanista, el derecho penal de la culpabilidad debe perecer. El principio de culpabilidad parte de supuestos insostenibles a la luz de la ciencia contemporánea, esto es, que es posible reprochar una conducta porque su autor podía decidir actuar de manera distinta. Tanto el determinismo como el indeterminismo convierten al principio de culpabilidad en un sinsentido. Sin uno de sus principios fundamentales el derecho penal solo puede ser reformulado o abolido.

Múltiples autores, recientemente entre ellos el profesor Demetrio Crespo, han intentado salvar al derecho penal con teorías compatibilistas. Ahora bien, en el pasado ya la Escuela de Frankfurt ha planteado el rechazo del libre albedrío como fundamento de la culpabilidad al plantear que no debe haber un juicio de reproche, sino más bien un límite que sea proporcional al acto y la sanción. ${ }^{53}$ Jakobs, por su parte, plantea que la responsabilidad criminal no se preocupa por la voluntad (que él entiende como libre albedrío): "Bien es cierto que la culpabilidad está relacionada con la libertad, pero no con la libertad de la voluntad, con el libre albedrio, sino con la libertad de autoadministrarse, esto es de administrar la cabeza y el ámbito de organización propios". 54

Sobre lo que expone Jakobs, su argumento tambalea por la misma afirmación que realiza sobre la posibilidad de que el ser humano puede administrar la cabeza. Está claro que el ser humano, la mente y su cuerpo son uno solo, y no existe dentro de su cabeza el verdadero yo inmaterial o un fantasma detrás de la máquina que administra la cabeza y el comportamiento. Por otra parte, Jakobs cae en un problema de definición ¿qué implica la posibilidad de administrar la cabeza?

Mírese el asunto desde otra perspectiva. El comportamiento humano obedece a factores neurobiológicos y ambientales. Si una de las máximas de la ciencia es que un experimento repetido en las mismas

\footnotetext{
${ }^{53}$ BALMACEDA, G.; Estudios de Derecho Penal General: una aproximación a la teoría del delito y de la pena, Bogotá, Ediciones Nueva Jurídica y Universidad de la Sabana, 2015.

${ }^{54}$ JAKOBS, G.; "El Principio de Culpabilidad”, Anuario de derecho penal y ciencias penales, 45, 3, 1992, p.1082.
} 
condiciones arroja el mismo resultado, la conducta humana de un "criminal" nunca pudo ser distinta. Si la vida de una persona que cometió un delito se pudiese repetir una y otra vez, bajo exactamente las mismas condiciones, inevitablemente el mismo resultado sucederá: la infracción a la ley penal. En otras palabras: si la persona crece en el mismo entorno social, ambiental, cultural y económico; con la misma herencia genética; desarrolla la misma estructura y funcionamiento cerebral y absolutamente todo ocurrió de la misma manera, no existe la posibilidad de que hubiese podido actuar de manera distinta. ¿Pudo administrar la cabeza, como diría Jakobs? ¿Tenía la intención, la voluntad, la conciencia o la capacidad de actuar como actuó? Nuestra respuesta es negativa.

Por otra parte, mucho se ha escrito sobre las bondades del derecho penal como un límite. Ferrajoli, por ejemplo, se refiere a la doble finalidad preventiva frente al delito, pero también, frente a la venganza o justicia por propia mano. ${ }^{55}$ Esto trae consigo el error de considerar al derecho penal como única forma de control social para la evitar venganza privada, además de implicar expropiar el conflicto a las partes involucradas, en lugar de darles voz en la búsqueda de soluciones restaurativas.

Otros autores, desde el planteamiento de Franz von Liszt de que el derecho penal es la Carta Magna del delincuente, han postulado que este es un límite a pretensiones político-criminales, desde el cual el ofensor podría contar con seguridad jurídica y ampararse en el principio de legalidad. ${ }^{56}$ Sin embargo, por más interesantes planteamientos dogmáticos, el derecho penal sigue manifestándose de manera brutal e indigna, construyéndose sobre supuestos metafísicos imposibles. Por esta razón, es claro que ni la teoría de la pena ni el derecho penal han logrado servir de límite al dolor en el poder punitivo; la práctica penitenciaria funciona ajena al discurso penal. ${ }^{57}$

Es por eso que consideramos que, si bien interesantes y desafiantes intentos se han hecho por salvar al derecho penal, ello es un gran despropósito. Cualquier propuesta que excluya el principio de culpabilidad y el libre albedrío es todo menos derecho penal. Podrá llamarse como se quiera: sistema de medidas de seguridad, herramienta de control social formal, pero no será más derecho penal, porque no habrá nada que penar, castigar o reprochar.

\footnotetext{
${ }^{55}$ FERRAJOLI, L.; Derecho y razón, teoría del garantismo penal. Madrid, Editorial Trotta, S. A., 1995.

${ }^{56}$ ZAFFARONI, E.; Tratado de Derecho Penal Parte General, Buenos Aires, Ediar, 1998.

${ }^{57}$ SIERRA, C.; "La innecesaria reinserción social en el paradigma social de la modernidad", en Los riesgos del punitivismo, presunción de inocencia e indignidad carcelaria en Colombia, Bogotá, Universidad Externado de Colombia, 2019
} 
Lo cierto es que el derecho penal de la vida real no es valioso; poco aporta a la realidad social y sí causa exacerbado sufrimiento humano. Pareciera que existe un miedo generalizado a perder ese constructo llamado derecho penal. Más aún, parece que existe un miedo generalizado a perder el libre albedrío; pero no es posible perder algo que nunca se ha tenido. El derecho penal no es útil, es infrahumano, cruel y degradante. Como veremos en adelante, no es la única, ni la mejor alternativa. Sobre este análisis dogmático, será imprescindible desarrollar a profundidad, en trabajos futuros, los argumentos desde las distintas posiciones doctrinarias.

\subsection{Existen alternativas humanas al derecho penal}

Sin culpabilidad el derecho penal sólo podría reformular su dogmática a partir de la responsabilidad objetiva, lo que implicaría un retroceso humano, constitucional y legal, hacia un derecho penal totalitario y de la peligrosidad. Por consiguiente, sostenemos la necesaria abolición del derecho penal como método de control social formal. Para su reemplazo proponemos que las situaciones problemáticas que conducen a lesiones de bienes jurídicos puedan resolverse de manera humana y digna mediante la justicia civil, la justicia restaurativa, la justicia terapéutica y el aprendizaje de los paradigmas alternativos de justicias indígenas.

La justicia civil es capaz de solucionar, sin brutalidad, situaciones problemáticas que puedan ser compensadas y tasadas. La justicia restaurativa, por su parte, rechaza la cultura del castigo y la venganza, para buscar una justicia humana que restaure los lazos sociales que quebranta el delito. Con la justicia restaurativa, los implicados e interesados en la resolución de las situaciones problemáticas tienen una voz sobre la forma como deberían solucionar su conflicto, en lugar de sufrir la expropiación del conflicto por parte del Estado y su brutal sistema penal. Con la justicia terapéutica como norte, es posible priorizar soluciones que mejoren el bienestar psicológico de las personas implicadas en un conflicto, para entender la complejidad de las interacciones sociales, y plantear mejores leyes con mejores aplicaciones prácticas. Finalmente, en países tan culturalmente diversos como los latinoamericanos, es posible aprender de las cosmovisiones indígenas para reconstruir un sistema de justicia lejano al retribucionismo y a la venganza. Es posible aprender de nuestras comunidades indígenas formas restaurativas de solucionar los conflictos.

\subsection{La prisión causa efectos neuropsicológicos negativos y debe abolirse}


La pena de prisión es la pena principal en los ordenamientos jurídicos contemporáneos. En Juicio a la prisión: una evaluación crítica, Thomas Mathiesen, denuncia lo que hoy ya es un hecho notorio: la abrumadora evidencia empírica señala que la cárcel no cumple ninguna función:

[...] "los fines de la cárcel no se logran. No se rehabilita a los presos. No se disuade a otros de cometer delitos. No se inhabilita a los presos, sino que mantienen -en realidad, incrementan- su capacidad de cometer delitos, tanto dentro como fuera de los muros de la cárcel. No se logra justicia. Cuando se la evalúa en términos de los propios objetivos declarados, la cárcel es un completo fracaso". 58

Con los avances en la neuropsicología ahora es posible visualizar los efectos que la prisionalización, el aislamiento y los ambientes penitenciarios tienen sobre el bienestar psicológico de las personas y su integridad neurológica. Meijers et al realizaron un estudio en una prisión holandesa donde se comprobó que las funciones cerebrales relacionadas con la autorregulación disminuyen después de 3 meses de encarcelamiento.

"Nuestro estudio sugiere que 3 meses de prisión en un entorno empobrecido pueden conducir a una reducción del autocontrol, medido como una mayor toma de riesgos y una reducción del rendimiento de la atención. Este es un hallazgo significativo y socialmente relevante, ya que los presos liberados pueden ser menos capaces de llevar una vida legal que antes de su encarcelamiento y pueden ser más propensos a comportamientos impulsivos de riesgo. En otras palabras, el entorno empobrecido puede contribuir a un mayor riesgo de reincidencia". ${ }^{9}$

Sjors Ligthart et al, analizaron dicho estudio y argumentaron que los efectos negativos sobre el funcionamiento cerebral de las personas que son privadas de su libertad podrían incluso vulnerar las convenciones internacionales que prohíben la tortura y los tratos crueles, inhumanos y degradantes ${ }^{60}$. Si esto sucede en prisiones de países desarrollados, es posible inferir que las condiciones exponencialmente más graves que se viven en las cárceles de países latinoamericanos, como Colombia, vulneran de manera absoluta la dignidad humana de quienes se encuentran privados de su libertad. La cárcel, entonces, antes de servir para lo humano, sirve para lo inhumano. Produce graves efectos neuropsicológicos de quienes

\footnotetext{
${ }^{58}$ MATHIESEN, T.; Juicio a la prisión: una evaluación crítica, Buenos Aires, EDIAR, 2003, p.32.

${ }^{59}$ MEIJERS J. et al.; "Reduced Self-Control after 3 Months of Imprisonment; A Pilot Study”, Front. Psychol, 9:69, 2018.

${ }^{60}$ LIGTHART, S. et al.; "Prison and the Brain: Neuropsychological Research in the Light of the European Convention on Human Rights", New Journal of European Criminal Law, vol. 10, no. 3, 2019.
} 
deben permanecer allí; lo peor, sin cumplir ninguna función más allá de aislar al individio del medio social y colocarlo en "cuarentena". La prisión, al igual que el derecho penal, debe ser abolida.

\subsection{La neurociencia, la criminología y la sociología pueden prevenir}

Desde la sociología se ha denunciado la existencia de hechos sociales como la extrema desigualdad, la pobreza, la marginalidad y la exclusión social. La neurociencia puede explicar cómo estos hechos sociales afectan el bienestar psicológico de las personas y dejar huellas en las estructuras neuronales. La falta de alimentación, el estrés, la agresión física y psicológica, la estigmatización y demás factores de riesgo pueden producir efectos neuropsicológicos adversos que le interesan al estudio criminológico. Con estos factores estudiados, es posible plantear programas de prevención que logren evitar la ocurrencia de situaciones problemáticas relacionadas con la agresividad, la impulsividad, la falta de empatía, y demás. En este contexto, la neurosociología surge como un campo para el análisis social transdisciplinario, para conectar sociología, cultura y neurociencias, evitando enfoques reduccionistas.

\subsection{El incompatibilismo humanista como límite}

Proponemos, como se mencionó anteriormente, al incompatibilismo humanista como una propuesta que, desde la filosofía de la ciencia, sirva de límite de contención a propuestas totalitaristas, peligrosistas e instrumentalizadoras del ser humano. Los derechos y la dignidad humana deben dirigir cualquier desarrollo que se de en la justicia, en la ciencia y en los avances neurotecnológicos. El incompatibilismo humanista, en adelante, fungirá como la base filosófica del neuroabolicionismo penal.

En este contexto, debates como la "mejora moral", o la intervención con neurotecnologías en el encéfalo de personas que infringen la ley y presentan patologías reales, debe producir reflexiones sobre los límites del Estado, la importancia del consentimiento informado y los llamados "neuroderechos humanos". Sin duda existen trastornos mentales que le importan a la neurocriminología, frente a los que el Estado debe ofrecer una intervención humana para reducir el dolor que estos trastornos provocan al paciente y a su entorno social. Hacia el futuro, las neurociencias y las neurotecnologías presentarán alternativas interesantes para intervenir en el cerebro de las personas y evitar futuros comportamientos antisociales y desviados, pero, para ello, deberá ser imprescindible comprender la dignidad humana y el consentimiento como límites. No todo comportamiento desviado es resultado de una psicopatología, pero ciertos trastornos mentales sí son factores de riesgo reales para los comportamientos antisociales. No se trata de 
la entrada de enfoques peligrosistas con pretensiones de neuropredicción del comportamiento desviado, que deben ser rechazados con firmeza, sino de reivindicar la función social de las disciplinas de salud mental para reducir el sufrimiento humano.

\section{Conclusiones}

En el presente artículo se abordó las nociones de determinismo e indeterminismo para comprender las discusiones que desde la filosofía se ha dado sobre el libre albedrío. Se introdujo a las teorías científicas para comprender el origen de la discusión del compatibilismo e incompatibilismo. Posteriormente, se planteó el problema que la neurociencia ha creado a partir de las investigaciones de Libet y demás, que ponen en la cuerda floja al principio de culpabilidad penal. Luego se mencionó la propuesta del profesor Eduardo Demetrio Crespo denominada compatibilismo humanista y se realizaron algunas críticas. Más adelante, se introduce al incompatibilismo humanista como una contrapropuesta y como la base filosófica de una nueva visión abolicionista complementaria: el neuroabolicionismo penal. El trabajo culminó con el planteamiento de cinco postulados básicos de dicha propuesta abolicionista.

A manera de conclusión, es posible sostener que el incompatibilismo humanista es una postura que, desde la filosofía y el derecho, ofrece una visión prometedora y alternativa para abolir el dolor estéril y cruel que se promueve mediante el derecho penal como mecanismo de control social. Dicha postura se propone comprender científicamente el comportamiento humano para abandonar nociones arcaicas sobre la responsabilidad penal. En adelante, el incompatibilismo humanista ofrece unas bases claras para plantear una alternativa humanista que busque la abolición del derecho penal. Los retos por delante son grandes, pues será necesario ampliar el desarrollo de los postulados básicos del neuroabolicionismo penal para conducir a una gran reflexión sobre la forma como se causa dolor mediante las estructuras formales de control social y los programas alternativos al derecho penal. Por otra parte, es necesario reconocer el carácter paulatino del tránsito social y jurídico, hacia una cultura restaurativa y abolicionista del derecho penal a largo plazo. Por consiguiente, hacemos un llamado a investigadores de todas las áreas del conocimiento para que se vinculen a esta nueva discusión sobre el futuro que queremos construir para nuestra sociedad global y sus sistemas de justicia.

\section{Bibliografía}

ADAMS, B. y PETRUCCIONE, F.; "Quantum effects in the brain: A review”, AVS Quantum Science, Vol. 2. N.2, 2020. https://doi.org/10.1116/1.5135170 
BALMACEDA, G.; Estudios de Derecho Penal General: una aproximación a la teoría del delito y de la pena, Bogotá, Ediciones Nueva Jurídica y Universidad de la Sabana, 2015.

CARNEVALI, Raúl.; "Derecho penal como ultima ratio. Hacia una política criminal racional”, Ius et Praxis, Vol. 14, n.1, 2008, pp.13-48. http://dx.doi.org/10.4067/S0718-00122008000100002

CHRISTIE, N.; Los límites del dolor, Ciudad de México, Fondo de Cultura Económica, 1998.

DEMETRIO, E.; "Compatibilismo humanista: una propuesta de conciliación entre neurociencias y derecho penal", en Neurociencias y derecho penal: nuevas perspectivas en el ámbito de la culpabilidad y tratamiento jurídico-penal de la peligrosidad, Madrid, Edisofer S.L, 2013, pp. 17-42

CÓRDOBA, M.; “Culpabilidad”, en: Lecciones de Derecho Penal Parte General, Bogotá, Universidad Externado de Colombia, 2011, pp. 359-369.

DE BROGLIE, L.; "Recherches sur la théorie des quanta", Paris, Annales De Physique III, 1925.

EASTWOOD, M.; "Heisenberg's uncertainty principle", QJM: An International Journal of Medicine, Vol.110, N.5., 2017, pp 335-336. https://doi.org/10.1093/qimed/hcw193

FELDMAN, D.; Chaos and Fractals: An Elementary Introduction, Oxford, Oxford University Press, 2012.

FERRAJOLI, L.; Derecho y razón, teoría del garantismo penal. Madrid, Editorial Trotta S. A., 1995.

GLANNON, W.; Brain, Body, and Mind: Neuroethics with a Human Face, Oxford, Oxford Scholarship Online, 2011.

GIMBERNAT, E.; “¿Tiene un futuro la dogmática jurídicopenal?”, en: Problemas actuales de Derecho penal y procesal, Salamanca, Universidad de Salamanca, 1971.

GUGGISBERG A, et al.; Timing and awareness of movement decisions: does consciousness really come too late? Front Hum Neurosci., 7:385, 2013. https://doi.org/10.3389/fnhum.2013.00385

HAGGARD, P. y EIMER, M.; "On the relation between brain potentials and the awareness of voluntary movements", Experimental Brain Research, Vol.126, 1999, pp. 128-133. https://doi.org/10.1007/s002210050722

HAMEROFF, S. y PENROSE, R.; "Orchestrated reduction of quantum coherence in brain microtubules: A model for consciousness", Mathematics and Computers in Simulation, Vol.40, 3-4, 1996, pp 453-480. https://doi.org/10.1016/0378$\underline{4754(96) 80476-9}$

HARRIS, S.; Free will, Nueva York, Simon \& Schuster, 2012.

HASSEMER, W.; "Neurociencias y culpabilidad en Derecho penal", InDret V2., 2011, pp. 1-14. https://indret.com/neurociencias-y-culpabilidad-en-derecho-penal/

HOEFER, C.; "Causal Determinism", The Stanford Encyclopedia of Philosophy. Edward N. Zalta (ed.), 2016. https://plato.stanford.edu/archives/spr2016/entries/determinism-causal/

INPEC.; Tableros Estadísticos: Nivel académico Intramural, Bogotá, INPEC, 2020. http://www.inpec.gov.co/estadisticas/tableros-estadisticos

JAKOBS, G.; "El Principio de Culpabilidad”, Anuario de derecho penal y ciencias penales, 45, 3, 1992, pp. 1051-1084.

JAMES, W.; "The dilemma of determinism", en: The Will to Believe: And Other Essays in Popular Philosophy, Cambridge, Cambridge University Press, 2014, pp. 145-183. https://doi.org/10.1017/CBO9781107360525.006

LAPLACE, P.; A Philosophical Essay on Probabilities, Londres, Chapman \& Hall, Limited, 1902.

LIBET, B. et al.; "Time of conscious intention to act in relation to onset of cerebral activity (readiness-potential). The unconscious initiation of a freely voluntary act", Brain: a journal of neurology, Vol.106, 3, 1983, pp. 623-642. https://doi.org/10.1093/brain/106.3.623

LIGTHART, S. et al.; "Prison and the Brain: Neuropsychological Research in the Light of the European Convention on Human Rights", New Journal of European Criminal Law, vol. 10, no. 3, 2019, pp. 287-300. http://doi.org/10.1177/2032284419861816

LOCKE, J.; An Essay Concerning Human Understanding, Pensilvania, The Pennsylvania State University, 1999. 
MARAIS, A. et al.; "The future of quantum biology", J. R. Soc. Interface, Vol. 15, N. 148, 2018, pp. 1-14. http://doi.org/10.1098/rsif.2018.0640

MATHIESEN, T.; Juicio a la prisión: una evaluación crítica, Buenos Aires, EDIAR, 2003.

MCKENNA, M. y PEREBOOM, D.; Free Will. A Contemporary Introduction, Nueva York, Routledge, 2016.

MEIJERS J. et al.; "Reduced Self-Control after 3 Months of Imprisonment; A Pilot Study", Front. Psychol, 9:69, 2018. http://doi.org/10.3389/fpsyg.2018.00069

MELE, A.; Free: Why Science Hasn't Disproved Free Will, Oxford, Oxford University Press, 2014

MUÑOZ, J.; "Mecánica Cuántica y Libre Albedrío: Cinco Cuestiones Fundamentales”, Principia: An International Journal of Epistemology, Vol, $19 \mathrm{~N}, 1,65,2015$. https://doi.org/10.5007/1808-1711.2015v19n1p65

PENROSE, R.; The Emperor's New Mind: Concerning Computers, Minds, and the Laws of Physics, Nueva York, Oxford University, 1989.

PEREBOOM, D.; Living Without Free Will, Cambridge, Cambridge University Press, 2003.

ROXIN, C.; Derecho Penal parte general, Tomo I: Fundamentos, la estructura de la teoría del delito, Madrid, Civitas, 1997.

SÁNCHEZ-CAÑIZARES, J.; “ES relevante la mecánica cuántica para la comprensión científica del problema mentecerebro?", en 60 preguntas sobre ciencia y fe respondidas por 26 profesores de universidad, Madrid, Editorial Stella Maris, 2014.

SIERRA, C.; "La innecesaria reinserción social en el paradigma social de la modernidad", en Los riesgos del punitivismo, presunción de inocencia e indignidad carcelaria en Colombia, Bogotá, Universidad Externado de Colombia, 2019.

SMART, J. y HALDANE, J.; Atheism and Theism, Malden, Blackwell Publishing Ltd, 2003.

SMIT, H. y HACKER, P.; "Seven Misconceptions About the Mereological Fallacy: A Compilation for the Perplexed", Erkenn, 79, 2014, pp. 1077-1097.

SOON, C. et al.; "Unconscious determinants of free decisions in the human brain", Nat Neurosci, V.11, 5, 2008, pp. 543-545. https://doi.org/10.1038/nn.2112

SOON, C. et al.; "Predicting free choices for abstract intentions", Proceedings of the National Academy of Sciences of the United States of America, 110, 15, 2013, pp. 6217-6222. https://doi.org/10.1073/pnas.1212218110

TREVENA J, y MILLER J.; Brain preparation before a voluntary action: evidence against unconscious movement initiation. Conscious Cogn., 19(1), 2010, pp. 447-456. https://doi.org/10.1016/j.concog.2009.08.006

VANNEY, C.; "Interpretaciones de la mecánica cuántica”, Diccionario Interdisciplinar Austral, 2016.

VAN INWAGEN, P.; An Essay on Free Will, Oxford, Clarendon Press, 1983.

WACQUANT, L.; Las cárceles de la miseria, Buenos Aires, Manantial, 2000.

ZAFFARONI, E.; Tratado de Derecho Penal Parte General, Buenos Aires, Ediar, 1998. 